Journal of Educational Administration

Emerald

Journal of Educational Administration

Generating change from below: what role for leadership from above?

\begin{tabular}{|r|l|}
\hline Journal: & Journal of Educational Administration \\
\hline Manuscript ID & JEA-07-2016-0074.R3 \\
\hline Manuscript Type: & Research Paper (Qualitative) \\
\hline Keywords: & $\begin{array}{l}\text { Teacher leadership, Change, Distributed leadership, Licensed leadership, } \\
\text { Teacher professional development, Organic leadership }\end{array}$ \\
\hline \multicolumn{2}{|l}{} \\
\hline
\end{tabular}

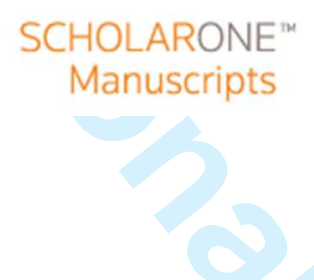




\title{
Generating change from below: what role leadership from above?
}

\begin{abstract}
:
Purpose: In recent years the benefits of distributed leadership have often assumed the status of an unchallengeable orthodoxy. There is a general acceptance that leadership is best when it is dispersed. In reality this is often little more than a form of 'licensed leadership' in which those working in subordinate roles can only exercise their leadership in tightly prescribed contexts. This article investigates the contribution of teacher professional development to promoting a more optimistic vision of teacher leadership and, ultimately, organisational change. It explores the role of leadership 'from above' in supporting classroom teachers to engage with and sustain change.
\end{abstract}

Design: The study, which was situated in the Republic of Ireland, employed a case study approach with 20 participants in five urban disadvantaged schools.

Findings: The article seeks to demonstrate how a professional development initiative was used to promote significant and sustained change in four of the five case study schools.

Implications: It argues that in order to understand sustained change in schools it is necessary to better understand the complex ways in which leadership from above can generate change agency from below.

Originality: This article offers a critical perspective in relation to mainstream distributed leadership theory and practice.

Keywords: teacher leadership, change, distributed leadership, licensed leadership, teacher professional development. 


\section{Introduction}

The concept of change in education is inextricably linked with the idea of school improvement. This is often reflected in the scale and pace of policy changes as governments across the world strive to enhance pupil outcomes (Ball, 2013; Bell and Stevenson, 2006; Rizvi and Lingard, 2009). Improvement is increasingly characterised as raised performance in international assessments such as PISA (Sellar and Lingard, 2013). In a globalised world where knowledge is seen as central to securing competitive advantage then strong performance in internationally benchmarked assessments has become a key objective of policy. However these policy changes are taking place in a time of austerity and a culture of isolated privatism (O'Sullivan, 2011) which may make implementation difficult. Central to the implementation process is the pivotal role of leadership (Day et al. 2009) in managing change with much analysis about what leaders can do to progress the school improvement agenda. Investing in teachers as change-agents through supporting collaborative models of professional development may support school improvement. Within this article we conceive of professional development as the "processes, activities and experiences that provide opportunities to extend teacher professional learning" which is considered to be "the growth of teacher expertise that leads to improved student learning" (NSW, Institute of Teachers, 2012, p 3).

The objectives of this article are threefold: first, to explore the possible role of leadership in generating effective learning environments for teachers to engage with and sustain change; second, to explore the potential link between teacher professional development and institutional change; and third to demonstrate a form of 'organic leadership' where teachers may develop a collective responsibility for all pupils' learning. It will demonstrate how a collaborative professional development initiative was able to bring about change in five urban disadvantaged schools in the Republic of Ireland (ROI) and it will analyse the pivotal role of principals in this process. 
The article will describe the context of the study and the methodology employed along with results which present a form of organic leadership which seeks to integrate a 'change from below' approach with 'support from above'. The distinction in this article between 'below' and 'above' seeks to reflect the experience of schools as workplaces in which power is located within institutional hierarchies, formalised through managerial structures. While it is generally accepted that those who are more senior in the organisation have greater reserves of power than subordinates, in terms of both authority and influence (Lumby, 2016), a deeper analysis of power and the practice of leadership is required (Woods, 2016). For example those who are subordinate in such formal structures may also have the capacity to assert influence and generate change (Sachs, 2003). This article is concerned with how 'above' and 'below' influences can be combined to create a powerful, and lasting, energy for change. The potential is a form of organic leadership (King 2012) whereby teachers may be empowered from above to develop their agency in ways that foster a genuine collective responsibility for pupils' learning and where teachers may transcend being functional implementers of the latest policy. As such, the article seeks to challenge traditional and managerialist conceptions of leadership by making the case for a teacher leadership (Muijs and Harris, 2003) that goes beyond being 'licensed' in which those working in subordinate roles can only exercise leadership in tightly prescribed contexts. This article seeks a creative way through this tension rhetoric and reality of distributed leadership by focusing on how leadership from above can draw on professional development and professional learning to develop a genuine teacher leadership from below. In so doing, it aims to help increase understanding of teacher leadership as a concept, which has assumed a key role in educational leadership literature, but often remains under-developed and undertheorised (Torrance, 2013). The article aims to explore these concepts by focusing on findings from Irish case studies which addressed two key issues:

- To what extent may leadership from above support teachers to implement and sustain change?

- What factors may shape the changes in teachers' practice?

\section{Research Context}


The article reports from a study carried out in the ROI where the international move toward accountability and control is evident in The Education Act (Government of Ireland,1998, Section 5) and subsequent policies, under what Sugrue (2011, p 61) refers to as a 'Technology of Control'. Examples of this include the Whole School Evaluation Process and mandatory reporting of standardised test results to the Department of Education and Skills (DES), parents and school boards of management. The competing policy agendas of accountability and trust, teacher autonomy and standardisation all have an impact on teachers' and principals' professional learning experiences and practices with principals under pressure to manage and yet lead, compete and innovate (Sugrue, 2011). How principals carry out their role in the ROI depends on the context in which they work as two thirds of primary school principals are teaching principals with a maximum of 22 days administrative leave (Irish Primary Principals Network (IPPN), 2014). Noteworthy is that this study took place in large urban schools with non-teaching principals in a prevailing culture where isolated privatism is more valued than collective responsibility (O'Sullivan, 2011). Since the 1990s there has been "an explosion of related administrative and managerial tasks without any real change in the resource capacity of schools" (IPPN), 2014, p 9). This is compounded by the lack of clarity surrounding the role of the principal, the lack of leadership training - teachers are promoted without adequate preparation for the role, poor administrative supports and poor management structures (IPPN, 2014, p 12). A hierarchical system is outlined in legislation which requires that teachers carry out the duties that are assigned to them by or at the direction of the principal (Government of Ireland, 1998). In the absence of a current legislative framework outlining the role of the principal, schools "are expected to play a key role in maintaining the knowledge society and be a critical element in the achievement of national goals" (IPPN, 2014, p 9).

The study involved a collaborative professional development initiative which was carried out in five urban disadvantaged schools, as categorised by the Social Inclusion section of the DES. Collaborative professional development is defined as a directive requiring one to have 'specific plans to encourage and enable shared learning and support between at least two teacher colleagues on a sustained basis' (Cordingley et al. 2004, p 2). In this study it refers to the 2007 initiative which involved a classroom teacher, Special Educational Needs (SEN) teacher and 
principal from each of the five schools engaging in collaborative professional development over a period of eight to ten weeks, with the aim of improving the literacy outcomes of pupils in $3^{\text {rd }}$ class (average age 9) through the implementation of Peer Tutoring (Butler, 1999; Topping, 1988). The initiative was funded and supported by the Irish National Teachers' Organisation (INTO) (the largest Irish teachers' union). Funding consisted of all materials, the support of project facilitators and release time from school for teachers to engage with the professional development initiative. Additional support was provided in terms of school visits from a project facilitator during the implementation period and access to telephone and email support. At the time a small-scale project evaluation was undertaken to assess the perceived impact on pupil learning (King and Gilliland, 2009). In 2010 a further study involved a return to the same five schools to explore the impact of the original professional development initiative on teachers' professional learning three years on. The rationale for this study came from the literature which has identified a paucity of research centred on sustainability of teaching practices despite sustainability of practices being pivotal for school improvement (Baker et al. 2004; Priestley et al. 2011).

\section{The role of leadership in the change process}

While leadership is a complex and contested concept, it is widely acknowledged that it can be exercised in a manner that can have a significant impact on promoting and sustaining change (Fullan et al. 2005), and on the quality of teaching and learning in classrooms (Day et al. 2009; Kervin, 2007). It is therefore not surprising that leadership has been defined as 'a relationship of social influence' (Spillane and Coldren, 2011, p 76) where teachers' state of readiness for change may be influenced by the nature and quality of leadership ((National Council for Curriculum and Assessment, (NCCA, 2010). However change is also personal and professional and principals' sensitivity to this connection may be central to the success of new initiatives or changes (NCCA, 2010). Difficulties may arise where there is a mismatch between individual needs and those of the school or state, especially in a climate of standardisation and performativity where changes within schools are often imposed by principals through performance management (Bolam et al. 2005) or licensed by principals in line with the school improvement focus. In these situations leadership 
may be seen as the exercise of hierarchical power with teachers feeling like they are 'technicians carrying out someone else's policy' (Priestley et al. 2011, p 269) rather than having autonomy in relation to their own professional learning relevant to the needs of their pupils. Importantly, several researchers argue that teachers' primary concerns are focused at classroom level rather than national or global policy imperatives (Kitching et al. 2009). Therefore it is held that they need to understand the need for change in order to engage with change.

Acknowledging teachers as being at the centre of decision making around change is one of the key principles in understanding and engaging in adult learning (Knowles et al. 2005) to result in teacher ownership and responsibility for pupil's learning. If the focus is on teachers having agency then a social constructivist perspective on learning is arguably necessary which aligns well with the current conceptualisation of professional learning in Scotland which argues for increasing autonomy and collaborative engagement (Kennedy, 2011). It is important however that this collaboration is not in the form of 'contrived collegiality' (Hargreaves, 1994, p 196) which arguably reflects a more licensed, contained form of collaboration contrived by principals.

The actions of school leaders it is held may therefore have a significant impact on teachers' engagement with school improvement changes. Acknowledging that it can be very difficult for leaders to mediate the structures and constraints of external pressures the literature suggests that it is possible to support teachers in meaningful ways for lasting change and improvement. One such approach that has gained prominence in recent years is that of distributed leadership (Tian et al. 2016) which focuses on "interactions" where "influence and agency are widely shared" (Harris and DeFlaminis, 2016, p 141). Distributed leadership theory offers the possibility of a practical and democratic form of leadership structure in schools (Preedy, 2016) where all teachers' strengths are valued and supported regardless of any formal leadership positions they may hold. Acknowledging that while it is widely written about in the international literature, it is nevertheless inadequately theorised (Torrance, 2013; Tian et al. 2016) which has resulted in significant confusion in its definition and manifestations. 
To facilitate the possibility of distributing leadership as conceptualised above, professional trust and a shift in power from formal leaders to teachers in the classroom is required, which can be very difficult in a climate of accountability, control and performativity (Preedy, 2016). We describe this "dark side of distributed leadership" (Harris and DeFlaminis, 2016, p 143) as 'licensed leadership' whereby teachers are encouraged to exercise agency, but only to the extent that they serve managerially determined and imposed targets. In these contexts there is often much talk of leadership being distributed, and many school leaders may believe this is what they are doing. However, the reality is that teachers may experience little meaningful autonomy due to external accountability pressures promoting hierarchical and centralised approaches to leadership. Leadership is distributed only as long as those lower in the hierarchy work within parameters that have been defined for them by those with superordinate power. This is the conclusion of Burns and Darling Hammond (2014), based on their analysis of TALIS 2013 data, when they highlighted the gap in perception between principals and teachers about the extent to which each saw leadership as shared.

Hence, while the extension of leadership practices to all teachers is advocated in theory and policy rhetoric the practice of distributed leadership may not reflect the original aims (Torrance, 2012). Currently it is sometimes perceived as being 'the panacea to aid all that ail[s] education' (Torrance, 2012, p 3), despite very few empirical studies on distributed leadership in existence (Harris, 2008; Harris and DeFlaminis, 2016). However, findings from Torrance's small-scale empirical research project undertaken in Scotland clearly highlight that the practice of distributed leadership is 'context specific, socially constructed, negotiated, hierarchical' and largely dependent on the principals' endorsement and support (Torrance, 2012, p 3), illustrating again that the reality is often little more than a form of licensed leadership.

Despite distributed leadership being valued by principals it is not so visible in a reality where principals are accountable for learning and feel under considerable pressure to deliver demonstrable results, usually in the format of standardised test scores. Therefore in practice it seems to be limited to the school's or department's priorities and as such may not reflect a genuine approach to leadership and change 
from below. It therefore lies in contradistinction to a more organic form of leadership that is less strategic and involves more freedom to be creative and take risks; arguably essential components for school improvement despite it being challenging for leaders to try to build capacity but focus on outcomes, and to innovate but avoid mistakes (Bell and Bolam, 2010).

The challenge for leadership is to have the courage to 'let go' of leadership and to be willing to place their trust in their teachers' beliefs, values and judgements (European Commission, 2010). However, this may be particularly challenging for principals where teachers are often, and understandably, more concerned with what happens in their own classrooms than at whole school or national level (Kitching et al. 2009) often valuing individual privatism over collective responsibility. This is evidenced from findings from Pedder and colleagues' (2008, p 14) quantitative study with 329 responses from primary schools indicating that teachers are not inclined to link their professional development with 'strategic benefits such as school improvement'. At the same time, findings from a study in England indicated that in schools where leaders understand the potential of professional development for school improvement, it can result in real change (Opfer et al. 2011). However 'Professional development does not just happen - it has to be managed and led' (Earley and Bubb, 2004, p 80) or led and supported (NCCA, 2010). Principals can create organisational capacity (King, 2011), which includes investing in teachers through providing professional development and on-going support (Fullan et al. 2005) and in schools as learning organisations, both of which are fundamental to the change process (NCCA, 2010) and focus on educational leadership rather than performance leadership (Torrance, 2012, p 12). Overall then, leading a grassroots approach, from below, with top-down support from above may help to create a culture where teachers feel trusted, capable of change (Bubb and Earley, 2008) and have high levels of self-efficacy (Kitching et al. p 2009); all of which are necessary for lasting change.

\section{Professional development and institutional change}


Teachers have been acknowledged as change-agents in education practice 'through whom the most significant impact can be made' (NCCA, 2010, p 20). Therefore, focusing on teacher practice may be one of the most effective ways to make a difference to school improvement which some deem to have the largest effect which can be influenced (Hattie, 2003). Teaching practices can relate to what teachers do in their classrooms, as well as their professional knowledge, skills, attitudes and values (Evans, 2010). Central to this is the concept of teacher professional development.

While professional development is mandatory in many countries research has shown that some teachers feel little or no motivation to change their practices as a result of engaging in it (Bubb and Earley, 2008). In fact, many jurisdictions mandate a particular number of hours of professional development that teachers must complete with 'no requirement for teachers to improve their practice or even to learn anything' (Wiliam, 2011, p 28). This may in part reflect a managerialist approach to professional development, leading teachers to feel little connection with the professional development they engage in. Rather they experience it as irrelevant to their own perception of their professional needs (Stevenson, 2012). Alternatively it may be reflective of the contested notion of professional development, with many viewing it merely as 'input'. Rather than defining professional development by activities, courses or experiences, a focus on outcomes from these experiences and reflections on day-to-day classroom practices (Bubb and Earley, 2008, p 26), thus emphasising professional development as a 'third-order activity' (Cordingley et al. 2003, p 14), is arguably more likely to result in improved pupil outcomes (King, 2014). In this way, conceptualising professional development as a third-order activity highlights the importance of the three aspects of professional development: the experience itself, impact on teacher practices and thirdly impact on pupil outcomes.

Many governments across the world continue to invest in teacher professional development despite straitened times. Yet evidence of its impact remains difficult to ascertain. This is evidenced in the Irish context where in the recent Literacy and Strategy (DES, 2011, p 37) there was a call for "CPD courses to be accredited, adequately assessed and evaluated" with still no guidance or clarity as to how this is to be carried out. 
While there are no definitive characteristics to ensure a successful link will be established between teacher professional development and enhanced pupil outcomes, certain conditions have been accepted as being conducive to it (Guskey, 1991). One of these is the crucial role of school leadership (Opfer and Pedder, 2011) where principals courageously support teachers as change-agents, allowing them to identify their own professional development. This is reflective of a bottom up approach with support from above providing genuine teacher autonomy and facilitating the need for professional development to be related to individual teachers' needs in their classrooms (Kervin, 2007). Enabling teachers in this way acknowledges teachers' skills and values (Brain et al. 2006) and may help to develop 'organic leadership' where teachers are empowered to take responsibility for their own learning and that of their pupils. This lies in contradistinction to a practice which reflects licensed leadership whereby principals use their "social tactics" to convince teachers to work towards government-mandated policies (Diamond and Spillane, 2016, p 150).

\section{Methods}

The study encompassed a small-scale qualitative research project involving five case-study schools in the ROI to gain teachers' and principals' perspectives on the impact of a professional development initiative which had been carried out three years previously. It set out to explore the perceived short-term and long-term impact in an effort to fill the research gap relating to sustainability of professional development practices. Participant selection for the study was purposive as it involved returning to the same participants involved in the original study. In 2007 five schools were selected from 19 schools that responded to an advertisement in the Irish National Teachers' Organisation (INTO) (teacher union) magazine inviting schools to engage in a literacy initiative. Preference was given to those in designated urban disadvantaged schools with a single class grouping that was not participating in another literacy initiative. A total of 20 participants were interviewed, including 13 principals and leaders who were involved in the original project (seven of the original participants no longer worked at the same institution) and a further seven who had subsequently become involved. This included two new principals. 
An evidence-based theoretical framework was developed based on existing evaluation frameworks and extant literature to assess impact of the professional development initiative (King, 2014). This framework guided the research questions which explored the perceived impact of the professional development in the short and longer term along with how the school shaped changes in teachers' practices. . What followed was an inductive approach to data analysis and an exploration of themes within and across the five schools (Bryman, 2004) revealing leaders as key factors shaping teachers' practices.

It is important at this point to acknowledge the limitations of the study in relation to researcher positionality and size. One of us was directly involved in the original research looking at impact on pupils' outcomes in 2007-08. Some participants may have cast the researcher as an insider (Mercer, 2007). At the same time, with the focus on sustainability three years later, this arguably created some distance, whilst for seven of the participants who were newer to the project there had been no previous contact. Furthermore positionality issues were addressed by ensuring that data analysis was conducted in a systematic and transparent manner (Lincoln and Guba, 1985), with both researchers being engaged in a rigorous questioning of the data and the conclusions being drawn.

The limited number of cases in the study means that there is no claim to generalizability for findings, but rather additions to existing knowledge which may provide new understandings regarding similar contexts. It is our view therefore that the results, while drawn from ROI case studies, arguably have the potential for a much wider application, and we expect and hope they will have a 'relatability' (Hammersley, 1990) well beyond the specific contexts being described.

\section{Results and discussion}

The results are presented under the following headings: School leadership- initiating change; school leadership - implementing change; and school leadershipsustaining change. 
School leadership - initiating change:

Five schools (A-E) were involved in this professional development initiative. Significantly the initiative was brought to the attention of four out of the five principals by teachers. Two of these teachers had formal leadership roles in their schools while the other two were special educational needs teachers with no formal leadership roles. All four principals (schools B-E) were immediately willing for their school to take part in the initiative, thus reflecting the importance of what DarlingHammond and McLaughlin (1995, p. 598) identify as 'top-down support for bottomup reform; arguably reflective of a more optimistic view of distributed leadership. In School A the principal brought the professional development initiative to the attention of her staff and asked the literacy coordinator to support a class teacher and SEN teacher to engage with the initiative; thus reflective of a top-down approach where the principal has the authority and influence (Lumby, 2016).

The data from principals and teachers suggests a consensus about the literacy content being a motivating factor to participate in the initiative: 'We are a disadvantaged school so there is huge emphasis on literacy' (Principal, School D). Interestingly teachers only cited their own individual needs in relation to the initiative, consistent with the literature that posits that teachers are more inclined to view professional development benefits in terms of individual fulfilment (Pedder et al., 2008), and that they are more concerned with what happens at classroom level than school or department level (Kitching et al., 2009), arguably reflecting teacher leadership in terms of teaching and learning (Diamond and Spillane, 2016) instead of school improvement, the darker side of distributed leadership (Harris and DeFlaminis, 2016). This may also be seen as evidence of Björkman and Olofsson's (2009) argument that alignment between teachers' and principals' priorities is a key driving force, providing strong supportive pre-conditions for capacity-building for change, suggesting mutual benefits for both principals and teachers. Added to this were the personal interests of principals and teachers: 'literacy was my hobbyhorse' (Principal, School B) and 'I'm very interested in literacy' (Principal, School A); 'to help my own teaching and learning' and to help gain security of tenure (Class teacher, School A) and; I was looking for help in how I could do that [help the children improve their literacy] (Class Teacher, School E). Reconciling these interests is the challenge. Not only were principals interested in the product (literacy initiative), some 
were thinking more strategically and saw this process as a 'vehicle' for introducing collaborative practices between class teachers and SEN teachers in the school, thus helping them enact their vision for their school (King, 2011). Therefore, principals were happy to empower their teachers through distributed leadership (Tian et al. 2016) to do what they wanted them to do and felt they could not mandate:

I think if you mandate it then you always get resistance.

I do think who's at the top is very influential (Principal, School A).

Perhaps this is indicative of principals' agency where they were able to mediate the structures to achieve their own goals, which in this instance are reflective of departmental policy advocating collaborative practices. Top-down support in this way may also raise the question of whether distributed leadership is only used when principals' and teachers' aims are aligned arguably reflective of principals licensing or legitimizing practices (Woods, 2016). While the above participants' perspectives reflect the importance of aligning professional development with teachers' personal and professional needs, they may also indicate a culture of 'new managerialism' with a focus on teacher accountability and performativity; the darker side of distributed leadership (Harris and DeFlaminis, 2016). However they also represent a situation where teachers felt it appropriate to suggest engagement with the initiative, irrespective of their role in the school: 'Martina [pseudonym for the principal] is great. She's just very good for being open to ideas to try things' (Class teacher, with no formal leadership role, School B ), reflecting bottom-up change with top-down support, a more organic form of leadership).

School leadership - implementing change;

The literacy initiative was implemented in each of the five schools over a ten week period (including a training period for pupils) and involved a class teacher and SEN teacher collaboratively facilitating peer tutoring for pupils within the mainstream classroom four days a week. The design of the initiative meant that both teachers were involved in co-planning (for example, pairings of pupils and levels of readers), co-presenting (for example modelling of procedures for pupils, monitoring their learning), co-problem-solving (for example around books being too easy, pairings 
not working out) and co-processing (for example formative and summative assessment). Participants' perspectives strongly support evidence of principals supporting teachers through creating organisational capacity for change (King, 2011), suggesting an interdependence between principals and teachers. This initially involved principals securing a class teacher and SEN teacher willing to work together on the initiative. All principals were aware of the importance of teachers' willingness to engage with the literacy practice instead of mandating the practice in a bid to lead to teacher ownership and lasting change. 'You're not going anywhere by cracking the whip on anything like this' (Principal, School D). This is interesting given the external pressures of performativity and reflects the principal's awareness of the importance of teacher motivation and willingness to engage with change. Furthermore, principals provided time for teachers to collaborate for planning and reflecting: 'we were facilitated in having the opportunity to do it [collaborate]... within school time' (Class teacher, School B) which teachers felt attached value to the initiative. This non-contact time was moved to outside of school hours in subsequent years. However teachers valued this planning and reflecting time and had no problem engaging in it after school hours. Supporting teachers through provision of time has been cited as important for successful implementation (Cordingley et al. 2003); a finding that is important given that the real problem in education is that innovation after innovation is developed without really solving the problem of implementation (Sahlberg, 2012).

Creating organisational capacity was also reflected in four out of five of the principals showing evidence of conceptual knowledge of the literacy initiative which they developed through attendance at the professional development day, through observing the literacy practice and in some cases participating in the initiative at the first stage of implementation. This active participation in professional development is consistent with the role of leadership (Robinson et al. 2009) identified as having the largest impact on student outcomes. From this hands-on involvement principals were more aware of the challenges during the implementation period and therefore were better placed to offer support to teachers; indicative of a developing relationship achieved by principals and teachers working together or transformational leadership where leaders and teachers are united in trying to achieve their goals (Bass and Riggio, 2006). However, in school A where the principal brought the initiative to the 
attention of the literacy coordinator in a top-down approach, the practice did not survive past its initial ten week implementation period. During the interview the principal did not exemplify procedural or conceptual knowledge of the literacy practice. She spoke in generic terms about her own knowledge and experience of reading initiatives but did not refer to any specifics of the literacy initiative used in this study. Furthermore she had no direct involvement in the professional development day or the practice in the school, despite supporting teachers to engage with it.

While all principals supported teachers in the initial ten week implementation period further support was required for sustainability of practices for which little evidence exists despite being crucial for school improvement (Baker et al., 2004; Priestley et al., 2011). This study returned to the same five schools three years on to ascertain if schools had sustained the practice and if so how they did so.

School leadership - sustaining change:

In four out of the five schools the literacy practice was sustained, albeit it in different ways. However, in school A, where the literacy practice was initiated in arguably a more obviously managerialist approach, it was not sustained. Interestingly, it was written into the policy as an initiative for literacy but the class teacher who wanted to sustain the practice reported 'unfortunately it's not me who decides the learning support [SEN] [timetable] in the school', indicative of a lack of power and influence. The principal felt it was not possible to timetable it as "we all felt a little bit submerged'; 'We had to buy into those [other initiatives].') and so the practice was not licensed. This also highlights the pressure principals are under to perform and yet provide teachers with freedom, to be creative and take risks, but avoid mistakes (Bell and Bolam, 2010) which are essential components of school improvement. Interestingly, very different versions of the impact of state-mandated literacy initiatives being introduced were offered by the other four schools who saw alignment between initiatives:

We have different initiatives at most levels . . third and fourth [class] would have the Peer tutoring . . . and it's for a set number of weeks. It's just a matter of scheduling and I think 
different things suit the teachers at different levels (Principal, School B)

Each of the four schools found the space within the constraints and scheduled the initiative in subsequent years with one principal (School D) stating that if teachers value it...then l'd be happy to support it'. This is in direct contrast to the emerging managerialism above, and more in line with a trust-based professionalism as conceptualized by Harris and DeFlaminis (2016) with principals affording teachers autonomy and trusting them in judging what works best for their pupils (Sahlberg, 2007).

Even more significant was that two of the schools had changed principals and the practice was still sustained. The new principals clearly showed their conceptual understanding of the initiative and their belief in it as a means of increasing collaborative practices among teachers and enhancing pupils' learning. This raises the issue again of principals being involved in teaching and learning and facilitating awareness of practices at conceptual levels for sustainment (Baker et al. 2004; Robinson et al. 2009). Principals showed evidence of empowering teachers to create collaborative learning cultures and professional learning communities (King, 2011) for example encouraging and facilitating teachers to become leaders themselves through modelling practices for others (Goos et al. 2007), thus working towards a collective responsibility for pupils' learning. This empowerment led to diffusion of practices within each of the four schools with the number of teachers involved having doubled since its inception three years previously. Principals also ensured that teachers were not under pressure to participate. Interestingly a significant number of teachers who tended to resist new practices and changes did engage with the initiative having heard from other teachers how successful it was for their pupils in their classrooms. Additionally principals did identify and hire staff that are open to and value collaborative practices. What is highly significant about principals supporting teachers is that they did not micromanage the practice despite having supported it through timetabling, providing time and extra resources in subsequent years. Principals trusted their teachers and the most significant outcome and unintended consequence reported by all principals was the impact on teachers at a collective level, with 'a bigger openness to working together and team teaching' 
(School E), having 'a greater sense of team between support staff [SEN] and class teachers' (School B), and collaborative practice now being 'part of what we do' (School D). This cultural change marked a move from isolated privatism to collective responsibility (O'Sullivan, 2011). The legacy of the professional development initiative was much greater than the initiative itself with all schools reporting cultural changes which it is argued is the real agenda for school improvement (Stoll and Fink, 1996).

So despite a culture of performativity and standardisation, principals found spaces, courageously trusted their teachers' values and opinions and gave them the time and support to take risks as evidenced by one teacher's comment about what her principal said: 'I trust you completely in what you're doing. You are the experts in this area' (Principal, School D). This echoes Priestley and colleagues' (2011, p. 270) view arguing for engendering 'professional trust and a genuine shift in power to those at the chalk face' for successful reform.

\section{Conclusion - understanding the importance of organic leadership}

Results of the case studies considered in this article have indicated participants' perspectives of how practices can be sustained and how cultural changes can be realised in schools with appropriate educational infrastructure (Diamond and Spillane, 2016); a 'grassroots approach' (Bubb and Earley, 2008, p 19) where teachers, regardless of having formal leadership roles or not, were responsible for bringing the literacy initiative to the principals coupled with principals support: volunteering their schools for engagement in the initiative; showing teachers they valued it; participating directly in the professional development project; and facilitating the diffusion of practices to others by providing time and resources. Despite being under external pressures in an emerging culture of standardisation, accountability and performativity, principals claimed that they found the space to act within the complexities of a rapidly changing education system. Such approaches emphasise the importance of courage, and a willingness to take risks, as a feature of 
modern leadership. It is also reflective of principals using their own agency to mediate the structures in an approach best described as 'organic leadership'. These findings add to the current literature on distributed leadership theory and leadership theory in general in terms of further understanding of the "education infrastructure (structures that support and constrain learning and teaching" (Diamond and Spillane, 2016, p 151).

What distinguishes this from other models of leadership is the symbiotic relationship between support from above and the necessary element of leadership from below where principals courageously trusted in and valued their teachers' opinions and this was demonstrated through giving them genuine autonomy to pursue the initiative. In this conception of organic leadership power is something that is shared, rather than something that is released by one party, to be exercised by another, but only on terms determined by the former. The result was much more than the sustainability of a literacy initiative; but a powerful collective responsibility for pupils' learning. Whilst, inevitably, principals possessed formal power, in the form of authority, power, in the form of influence was best described as the outcome of a more collaborative process of co-construction between formal and informal leaders. In this way teachers were not only the product of their environment but were also its producers. Leadership was less hierarchical, but rather was fluid and networked.

Results of the study conducted at the case-study schools highlight the significant challenges of ensuring that change is not only implemented with success, but also, crucially, sustained over time. Although each case had its own contextual specificity we do believe the cases have important implications for policy and practice more widely. In particular this research highlights the considerable possibilities that exist when genuine teacher leadership is developed through collaborative PD. Such approaches can seem counter-intuitive in environments where high-stakes accountability often drives control and conformity. This provides a challenge for policy- makers, and school leaders, to focus on creating the conditions in which organic leadership can support teachers exercising leadership. After that they have to learn to let go. 


\section{References}

Baker, S., Gerston, R., Dimino, J. A. and Griffiths, R. (2004), "The Sustained Use of Research-Based Instructional Practice: A Case Study of Peer-Assisted Learning Strategies in Mathematics", Remedial and Special Education, Vol. 25 No. 1, pp. 5-24.

Ball, S.J. (2013), The Education Debate (Politics and Policy in the $21^{\text {st }}$ Century), Policy

Press, Bristol.

Bass, B. and Riggio, R. (2006), Transformational Leadership, 2nd edition, Lawrence Erlbaum Associates, New Jersey.

Bell, L. and Bolam, R. (2010), "Teacher Professionalism and Continuing Professional Development: Contested concepts and their implications for school leaders", In: Bush, T., Bell, L. and Middlewood, D. (Eds.) The Principles of Educational Leadership and Management, Sage, pp. 89-111.

Bell, L. and Stevenson, H. (2006), Education Policy: Process, Themes and Impact, Routledge, London.

Björkman, C. and Olofsson, A. (2009), "Qualitative Descriptions of Pre-conditions for Capacity-building in Schools", International Studies in Educational Administration, Vol. 37 No. (2), pp. 25-40.

Bolam, R., McMahon, A., Stoll, L., Thomas, S., Wallace, M., Greenwood, A., Hawkey,

K., Ingram, M., Atkinson, A. and Smith, M. (2005), Creating and Sustaining Effective Professional Learning Communities. RB637. Nottingham: DfES Publications. Available from http://dera.ioe.ac.uk/5622/1/RR637.pdf [Accessed 9 April 2017].

Brain, K., Reid, I. and Comerford Boyes, L. (2006), Teachers as mediators between educational policy and practice, Educational Studies, Vol. 32 No. 4, pp. 411423.

Bryman, A. (2004), Social Research Methods. 2nd edition, Oxford University Press. Oxford.

Bubb, S. and Earley, P. (2008), From self-evaluation to school improvement: The 
importance of effective staff development, CfBT Education Trust, Reading.

Burns, D. \& Darling-Hammond, L., (2014), Teaching Around the World: What Can TALIS Tell Us?, Stanford Center for Opportunity Policy in Education, Stanford, CA.

Butler, F.M. (1999), "Reading Partners: Students Can Help Each Other Learn to Read", Education and Treatment of Children, Vol. 22 No. 4, pp. 415-426.

Cordingley, P., Bell, M., Rundell, B. and Evans, D. (2003), The impact of collaborative CPD on classroom teaching and learning. In: Research Evidence in Education Library. London, EPPI-Centre, Social Science Research Unit, Institute of Education.

Cordingley, P., Bell, M. and Thomason, S. (2004), The impact of collaborative CPD on

classroom teaching and learning. Protocol: How do collaborative and sustained CPD and sustained but not collaborative CPD affect teaching and learning? [online] London, EPPI-Centre, Social Science Research Unit, Institute of Education. Available from:

$<$ http://eppi.ioe.ac.uk/EPPIWebContent/reel/review_groups/CPD/cpd_protocol 2.pdf $>$ [Accessed 27 May 2014].

Darling-Hammond, L. and McLaughlin, M.W. (1995), "Policies that Support

Professional Development in an Era of Reform", Phi Delta Kappan, Vol. 76, No. 8, pp. 597-604.

Day, C., Sammons, P., Hopkins, D., Harris, A., Leithwood, K., Gu, Q., Brown, E., Ahtaridou, E. and Kington, A. (2009), The impact of school leadership on pupil outcomes, Department of Children, Schools and Families, London.

Department of Education and Skills (DES). (2011). Literacy and numeracy for learning and life, DES, Dublin.

Diamond, J. B. and Spillane, J. P. (2016), "School leadership and management from a distributed perspective", Management in Education Vol. 30 No. 4, pp.147-154.

Earley, P. and Bubb, S. (2004), Leading and Managing Continuing Professional Development, Sage, London.

European Commission (2010), Improving Teacher Quality: the EU agenda. EAC.B.2 (2010) PSH. Brussels. Available from http://www.mv.helsinki.fi/home/hmniemi/EN Improve Teacher Quality eu ag enda 042010 EN.pdf [Accessed 9 April 2017].

Evans, L. (2010), Leadership for faculty development: confronting the complexity of professional development, presented at the annual meeting of the American Educational Research Association, Denver, Colorado. 
Fullan, M., Cuttress, C. and Kilcher, A. (2005), "8 forces for leaders of change", Journal of Staff Development, Vol. 26 No. 5, pp. 54-64.

Goos, M., Dole, S. and Makar, K. (2007), "Designing Professional Development to Support Teachers' Learning in Complex Environments", Mathematics Teacher Education and Development, Vol. 8 (Special Issue), pp. 23-47.

Government of Ireland (1998), The Education Act. The Stationery Office, Dublin.

Guskey, T.R. (1991), "Enhancing the Effectiveness of Professional Development Programs", Journal of Educational and Psychological Consultation, Vol. 2 No. 3, pp. 239-247.

Hammersley M. (1990), Reading Ethnographic Research, Longman, New York.

Hargreaves, A. (1994), Changing teachers, changing times: Teachers' work and culture in the postmodern age, Teachers College Press, New York.

Harris, A. (2008), "Distributed Leadership: According to the evidence", Journal of Educational Administration, Vol. 46 No. 2, pp. 172-188.

Harris, A. and DeFlaminis, J. (2016), "Distributed leadership in practice: Evidence, misconceptions and possibilities", Management in Education, Vol. 30 No. 4, pp. 141-146.

Hattie, J. (2003), Teachers Make a Difference. What is the research evidence?, presented at the Building Teacher Quality: What does the research tell us ACER Research Conference, Melbourne, Australia. [online] Available from: http://research.acer.edu.au/research conference 2003/4/ [Accessed 9 April 2016].

Irish Primary Principals Network (IPPN) (2014), Priorities for Principal Teachers- In Clear Focus, Líonra+, Cork, Ireland.

Kennedy, A. (2011), "Collaborative continuing professional development (CPD) for teachers in Scotland: aspirations, opportunities and barriers", European Journal of Teacher Education, Vol. 34 No. 1, pp. 25-41.

Kervin, L. (2007), "Supporting elementary teachers at the 'chalk-face': A model for inschool professional development", International Electronic Journal for Leadership in Learning, Vol. 11 No. 10 [online]. Available from University of Calgary at: <http://www.ucalgary.ca/iejll> [Accessed 3 December 2008].

King, F. (2011), "The role of leadership in developing and sustaining teachers' professional learning", Management in Education, Vol. 25 No. 4, 149-155. 
King, F. (2012), "Developing and sustaining teachers' professional learning: A case study of collaborative professional development", Doctoral thesis, University of Lincoln, Lincoln, UK.

King, F. (2014), "Evaluating the impact of teacher professional development: An evidence-based framework", Professional Development in Education, Vol. 40 No. 1, 89-111.

King, F. and Gilliland, A. (2009), "Peer tutoring: An inclusive approach to supporting reading: Case study in five disadvantaged schools", LEARN, Journal of the Irish Learning Support Association, Vol. 31, pp. 50-61.

Kitching, K., Morgan, M. and O'Leary, M. (2009), "It's the little things: exploring the importance of commonplace events for early-career teachers' motivation", Teachers \& Teaching, Vol. 15 No. 1, pp. 43-58.

Knowles, M. S., Holton, E. F. and Swanson, R. A. (2005), The adult learner, 6th edition,

Elsevier Butterworth-Heinemann, Burlington, MA. (Original work published 1973).

Lincoln, Y.S. and Guba, E.G. (1985) Naturalistic Inquiry, Sage, Newbury Park, CA.

Lumby, J. (2016), "Distributed leadership as fashion or fad”, Management in

Education, Vol. 30 No. 4), pp.161-167.

Mercer, J. (2007), "The challenges of insider research in educational institutions:

wielding a double-edged sword and resolving delicate dilemmas", Oxford Review of Education, Vol. 33 No. 1, pp. 1-17.

Muijs, D. and Harris, A. (2003), "Teacher leadership: Improvement through empowerment? An overview of research", Educational Management Administration and Leadership, Vol. 31 No. 4, pp. 437-448.

National Council for Curriculum and Assessment (NCCA) (2010), Leading and

Supporting Change in Schools, Discussion Paper. [online] Available from: http://www.ncca.ie/en/Old\%20Publications\%20listing/Leading_and_Supportin g_Change_in_Schools.pdf [Accessed 2 January 2011].

New South Wales (NSW) Institute of Teachers (2012), Continuing Professional

Development Policy - Supporting the Maintenance of Accreditation at Proficient Teacher/ Professional Competence. [online] Available from: http://www.nswteachers.nsw.edu.au/lgnitionSuite/uploads/docs/continuing\%2 Oprofessional\%20development\%20policy.pdf [Accessed 9 April 2017].

Opfer, V.D., Pedder, D. and Lavicza, Z. (2011), "The role of teachers' orientation to learning in professional development and change: A national study of teachers in England", Teaching and Teacher Education, Vol. 27 No. 2, pp. 443-453.

Opfer, V.D. and Pedder, D. (2011), "The Lost Promise of Teacher Professional 
Development in England", European Journal of Teacher Education, Vol. 34 No. 1, pp. 3-24.

O'Sullivan, H. (2011), "Leading and Managing Professional Learning in Schools", In: O'Sullivan, H. and West-Burnham, J. (Eds.) Leading and Managing Schools, Sage, pp. 111-125.

Pedder, D., Storey, A. and Opfer, V.D. (2008) Schools and continuing professional development (CPD) in England: State of the Nation research project report for the Training and Development Agency for Schools. [online.] University of Cambridge, UK. Available from: <http://www.tda.gov.uk/cpd-leader/effective$\mathrm{cpd} / \sim / \mathrm{media} /$ resources/cpd-leader/effective-cpdresearch/cpd statenation report survey.pdf> (Accessed 20 December 2010).

Preedy, M. (2016), “Distributed leadership: Where are we now?", Management in Education, Vol. 30 No. 4, pp. 139-140.

Priestley, M., Miller, K., Barrett, L. and Wallace, C. (2011), "Teacher Learning Communities and Educational Change in Scotland: the Highland Experience", British Educational Research Journal, Vol. 37 No. 2, pp. 265-284.

Rizvi, F. and Lingard, B. (2009), Globalizing Education Policy, Routledge, London.

Robinson, V., Hohepa, M. and Lloyd, C. (2009) School leadership and student outcomes: Identifying what works and why. [online] CUREE. Available from: http://www.curee.co.uk/files/publication/1260453707/Robinson\%20Summary \%20Extended\%20Version.pdf [Accessed 3 January 2013].

Robson, C. (2002), Real World Research, 2nd edition, Blackwell, Oxford.

Sachs, J. (2003), The Activist Teaching Profession, Open University Press, Buckingham.

Sahlberg, P. (2007), "Education policies for raising student learning: the Finnish approach", Journal of Education Policy, Vol. 22 No. 2, pp. 147-171.

Sahlberg, P. (2012), How can research help educational change? [online] Available from http://pasisahlberg.com/2012/04 [Accessed 9 April 2017].

Sellar, S. and Lingard, B. (2013), "The OECD and Global Governance in Education", Journal of Education Policy, Vol. 28, pp. 710-725.

Spillane, J. P. and Coldren, A. F. (2011), Diagnosis and Design for School Improvement: Using a Distributed Perspective to Lead and Manage Change, Teachers College Press, New York. 
Stevenson, H. (2012), "Teacher leadership as intellectual leadership: creating spaces for alternative voices in the English school system", Professional Development in Education, Vol 38, No. 2, pp. 345-360.

Stoll, L. and Fink, D. (1996), Changing Our Schools: Linking School Effectiveness and

School Improvement, Open University Press, Maidenhead.

Sugrue, C. (2011), "Autonomy and Accountability”, In: O'Sullivan, H. and WestBurnham, J. (Eds.) Leading and Managing Schools. Sage, pp. 59-74.

Tian, M., Risku, M., and Collin, K. (2016), "A meta-analysis of distributed leadership from 2002 - 2013: Theory development, empirical evidence and future research focus", Educational Management Administration \& Leadership, Vol. 44 No.1, pp.146-164.

Topping, K. (1988), The Peer Tutoring Handbook, Croom Helm, London.

Torrance, D (2012), "Distributed leadership: challenging five generally held assumptions. School Leadership and Management", presented at the annual conference of the International Professional Development Association, Birmingham, UK.

Torrance, D (2013), “Distributed leadership: challenging five generally held assumptions", School Leadership and Management, Vol. 33 No. 4, pp. 354372.

Wiliam, D. (2011), Embedded Formative Assessment. Bloomington, IN: Solution tree.

Woods, P. (2016), "Authority, power and distributed leadership", Management in Education, Vol. 30 No. 4, pp.155-160.

Yin, R.K. (1994), Case Study Research: Design and Methods. 2nd edition: Sage, Thousand Oaks, CA. 